\title{
Biosynthesis of Wax Esters in the Psychrophilic Bacterium Micrococcus cryophilus
}

\author{
By GEOFFREY M. LLOYD AND NICHOLAS J. RUSSELL* \\ Department of Biochemistry, University College, Cathays Park, P.O. Box 78, \\ Cardiff CF1 1XL, U.K.
}

(Received 11 February 1983; revised 22 March 1983)

\begin{abstract}
The biosynthesis of wax esters by the psychrophilic bacterium Micrococcus cryophilus has been investigated using radio-gas chromatographic analysis of the constituent fatty acid and fatty alcohol moieties. Degradation studies, using $\alpha$-oxidation, and the kinetics of labelling from radioactive precursors show that wax ester fatty alcohols are derived from fatty acids. Based on different labelling patterns in wax esters and phospholipids formed from acetate or a saturated fatty acid supplied exogenously, two pathways of wax ester biosynthesis are proposed. It is suggested that wax esters can be derived in the main from either a cytoplasmic or a membranebound pool of fatty acyl-coenzyme A thioesters and alcohols, depending on whether the fatty acid is synthesized endogenously or is supplied exogenously.
\end{abstract}

\section{INTRODUCTION}

The psychrophilic bacterium Micrococcus cryophilus contains relatively large amounts of wax esters, which represent $14 \%$ of the total lipid. The major wax esters are $C_{36}$ with one $(36: 1)$ or two (36:2) double bonds, with smaller amounts of $\mathrm{C}_{32}$ and $\mathrm{C}_{34}$ components, reflecting the predominance of 18:0 and 18:1 fatty acids and fatty alcohols (Russell, 1974; Russell \& Volkman, 1980). The unsaturated acids and alcohols are mainly $\Delta^{9}$ isomers; smaller amounts of $\Delta^{11}$ isomers are also present, particularly in the alcohols. Changes in growth temperature lead to changes in the unsaturation, chain length and proportion of $\Delta^{11}$ isomers (Russell \& Volkman, 1980). This is in direct contrast to the phospholipids, which contain exclusively $\Delta^{9}$ isomers, and which respond to growth temperature changes by altering chain length, but not unsaturation (Russell, 1974). It has been argued that all of these changes are part of a mechanism whereby the bacterium regulates its membrane fluidity in response to alterations of temperature.

Although wax esters are widespread in nature, there have been relatively few studies of their biosynthesis, especially in bacteria. The fact that the combination of fatty acids and fatty alcohols in the wax esters of $M$. cryophilus is random (Russell \& Volkman, 1980), suggests that the factors (e.g. temperature) that determine wax ester structure do so by regulating the nature of the acid and alcohol pools. The present paper gives the results of experiments designed to give information on the biosynthesis of the fatty acid and fatty alcohol moieties of the wax esters in M. cryophilus.

\section{METHODS}

Materials. Sodium [U-14 C]acetate (specific radioactivity, $59 \mathrm{mCi} \mathrm{mmol}^{-1} ; 2 \cdot 18 \mathrm{GBq} \mathrm{mmol}^{-1}$ ), $\left[1{ }^{-14} \mathrm{C}\right]$ palmitic acid (specific radioactivity, $59 \mathrm{mCi} \mathrm{mmol}^{-1} ; 2 \cdot 18 \mathrm{GBq} \mathrm{mmol}^{-1}$ ) and $\left[1-{ }^{14} \mathrm{C}\right]$ stearoyl-CoA (specific radioactivity, $49 \mathrm{mCi} \mathrm{mmol}^{-1} ; 1.81 \mathrm{GBq} \mathrm{mmol}^{-1}$ ) were purchased from Amersham. Sodium acetate and stearoyl-CoA were dissolved in water and the fatty acid was dissolved in ethanol/water $(1: 1, \mathrm{v} / \mathrm{v})$ and stored at $-20^{\circ} \mathrm{C}$. Control experiments indicated that the amount of ethanol added $(<0.1 \%$, by vol.) to bacterial cultures (see below) did not affect wax ester synthesis. Wax ester, fatty acid and fatty alcohol standards were obtained from Sigma. 
Growth of cultures. Batch cultures of $M$. cryophilus (ATCC 15174) were grown at $20^{\circ} \mathrm{C}$ (mean generation time $\simeq 4 \mathrm{~h}$ ) in a Casamino acids/salts medium to late-exponential phase of growth as described previously (Russell, 1974). These conditions maximized lipid yields whilst ensuring that growing cells were used.

Assay of wax ester synthesis. Radioactive precursors were added directly to growing cultures or to a lysate prepared by using a French pressure cell (Foot et al., 1983). At timed intervals samples (1 ml) were removed and added to $3.75 \mathrm{ml}$ chloroform/methanol $(1: 2, \mathrm{v} / \mathrm{v})$, which stopped the incorporation of precursor, and extracted the lipids (Foot, 1980). The lipids were washed in a two-phase stystem (Garbus et al. 1963) and wax esters were isolated by preparative TLC on $0.3 \mathrm{~mm}$ silica gel H plates (Merck) (Russell \& Volkman, 1980). Phospholipids, which remained at the origin, were also isolated (Sandercock \& Russell, 1980). The wax esters were saponified and the constituent fatty acids and fatty alcohols extracted; the whole was treated to form fatty acid methyl esters, reextracted and the esters separated from the alcohols by TLC (Russell \& Volkman, 1980). The radioactivity in lipid fractions was measured by liquid scintillation spectrometry using an Intertechnique PG 4000 spectrometer with external standards ratio facility for determination of quenching.

Assay of wax ester fatty acid and fatty alcohol synthesis. Cultures were incubated with radioactive precursors, and at timed intervals aliquots were centrifuged at $12000 \mathrm{~g}\left(r_{\mathrm{av}}=10.7 \mathrm{~cm}\right)$ for $10 \mathrm{~min}$ at $4{ }^{\circ} \mathrm{C}$. The bacterial pellet was extracted overnight in $10 \mathrm{ml}$ chloroform/methanol $(1: 1, \mathrm{v} / \mathrm{v})$, and the total lipid washed using the method of Garbus et al. (1963). The wax esters were saponified, and fatty acids methylated and separated from fatty alcohols by TLC as described above. The isolated fatty alcohols were acetylated using acetic anhydride (Kates, 1972).

Fatty acid methyl esters and fatty alcohol acetates were analysed by radio-GLC using a Pye Unicam GCD chromatograph equipped with flame ionization detectors, and connected to a 'Panax-Reigate series' radiogas detector system. The glass columns $(1.5 \mathrm{~m} \times 2.0 \mathrm{~mm}$ i.d.) were packed with $15 \%(\mathrm{w} / \mathrm{w})$ ethyleneglycol succinate silicone (EGSS-X) supported on 80-100 mesh Chromosorb W AW (Supelco, Philadelphia, U.S.A.) operated isothermally at $190^{\circ} \mathrm{C}$.

$\alpha$-Oxidation studies. The $\alpha$-oxidation of fatty acids or fatty alcohols, isolated from radioactive wax esters, was performed and the products analysed by radio-GLC as described previously (Sandercock \& Russell, 1980). Standard errors were calculated by the method of Dean \& Dixon (1951).

\section{RESULTS}

\section{Incorporation of radioactive precursors into lipids}

The radioactive precursors, sodium $\left[\mathrm{U}-{ }^{14} \mathrm{C}\right]$ acetate and $\left[1-{ }^{14} \mathrm{C}\right]$ palmitic acid were incorporated into lipids of $M$. cryophilus extremely rapidly, i.e. within a few seconds (Fig. $1 a, b$ ). Radioactive labelling of phospholipid reached a plateau after 15-30 min, whereas that of wax ester peaked between 2 and 30 min (depending upon the precursor) followed by a gradual decline. The amount of incorporation of radioactive sodium acetate into wax esters was $<5 \%$ of that in the phospholipids.

The kinetics of incorporation of radioactivity from the various precursors into the fatty acids and fatty alcohols was similar to that of the intact wax esters (Fig. $2 a, b$ ). However, close inspection of the data shows that for each precursor, incorporation into the fatty acid reached a peak value before incorporation into the fatty alcohol (Fig. $2 a, b$ ).

\section{Metabolism of wax ester fatty acids and fatty alcohols}

Analysis of the constituent fatty acids and fatty alcohols of the wax esters using radio-GLC allowed changes in their chain length and unsaturation to be followed. There was a large difference in the labelling patterns obtained using these two precursors, particularly when the time course of incorporation was followed (Tables 1 and 2). Initially, acetate was incorporated into $\mathrm{C}_{18}$ (mainly $\mathrm{C}_{18: 0}$ ) rather than $\mathrm{C}_{16}$ fatty acids and alcohols, which were progressively desaturated to $\mathrm{C}_{18: 1}(40 \%$ in fatty acid, $20 \%$ in fatty alcohol) (Table 1$)$. In complete contrast, although much larger amounts of palmitate were incorporated, the majority remained as $C_{16: 0}$ in both fatty acid and alcohol, which were only slowly elongated and/or desaturated (Table 2). The small amount of change in fatty acid was from $C_{16: 0}$ to $C_{18: 1}$, with little appearance of $C_{16: 1}$, whereas the fatty alcohol showed some change from $C_{16: 0}$ to $C_{16: 1}$ together with $C_{16: 0}$ to $\mathrm{C}_{18: 1}$. Thus, there was a small amount of elongation and desaturation of the fatty acids and fatty alcohols synthesized from palmitate. 


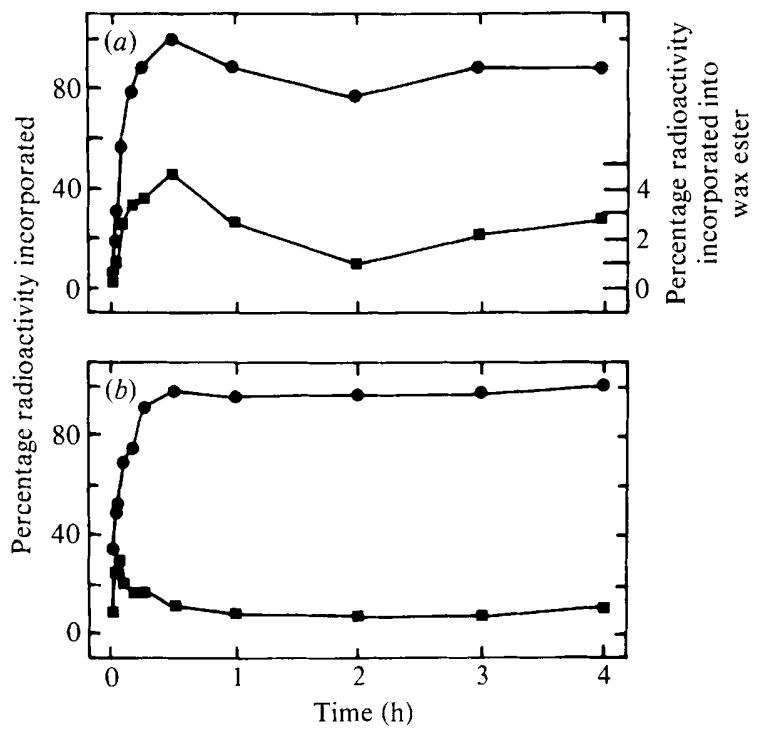

Fig. 1. Incorporation of sodium $\left[\mathrm{U}^{-14} \mathrm{C}\right]$ acetate and $\left[1-{ }^{14} \mathrm{C}\right]$ palmitic acid into major lipids of $M$. cryophilus. An exponentially growing culture $(25 \mathrm{ml})$ was incubated at $20^{\circ} \mathrm{C}$ with $125 \mu \mathrm{Ci}$ sodium [U$\left.{ }^{14} \mathrm{C}\right]$ acetate $(a)$ or $2.5 \mu \mathrm{Ci}\left[1-{ }^{14} \mathrm{C}\right]$ palmitic acid $(b)$. At intervals samples $(1 \mathrm{ml})$ were removed directly into chloroform/methanol, and the incorporation into phospholipids ( $O$; mean values, $n=4$ ) and wax esters ( $\square$; mean values, $n=2$ ), determined by TLC as described in Methods. The peak values of incorporation were $(a) 7.5 \%$ (822000 d.p.m.) and $0.4 \%$ (38000 d.p.m.) for phospholipid and wax ester, respectively and (b) 30.0\% (66000 d.p.m.) and 8.7\% (19000 d.p.m.) for phospholipid and wax ester, respectively.

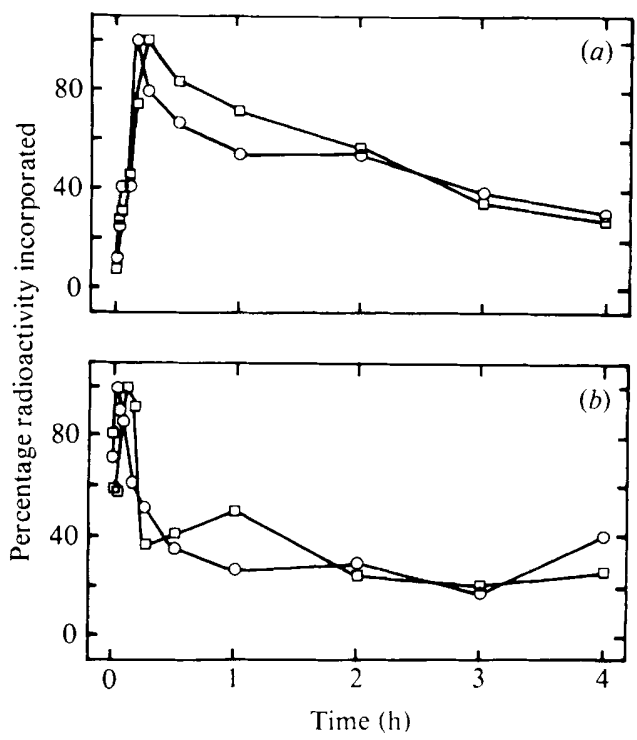

Fig. 2. Incorporation of sodium $\left[\mathrm{U}^{14} \mathrm{C}\right] \mathrm{acetate}$ and $\left[1-{ }^{14} \mathrm{C}\right]$ palmitic acid into wax ester acids and alcohols of $M$. cryophilus. An exponentially growing culture $(25 \mathrm{ml})$ was incubated at $20^{\circ} \mathrm{C}$ with $125 \mu \mathrm{Ci}$ sodium $\left[\mathrm{U}^{14} \mathrm{C}\right]$ acetate $(a)$ or $2 \cdot 5 \mu \mathrm{Ci}\left[1-{ }^{14} \mathrm{C}\right]$ palmitic acid $(b)$. At intervals samples $(1 \mathrm{ml})$ were removed directly into chloroform/methanol, and the incorporation into wax acid $(O$; mean values, $n=2)$ and wax alcohols ( $\square$; mean values, $n=2)$ determined by TLC as described in Methods. The peak values of incorporation were (a) $0.03 \%$ (3500 d.p.m.) and $0.07 \%$ (8000 d.p.m.) for wax acid and wax alcohol, respectively and (b) $2.5 \%$ (5500 d.p.m.) and 2.0\% (4500 d.p.m.) for wax acid and wax alcohol, respectively. 
Table 1. Distribution of radioactivity in wax ester acids and alcohols of $M$. cryophilus incubated with sodium $\left[U-{ }^{14} C\right]$ acetate

An exponentially growing culture $(350 \mathrm{ml})$ was incubated at $20^{\circ} \mathrm{C}$ with $175 \mu \mathrm{Ci}$ sodium $\left[\mathrm{U}-{ }^{14} \mathrm{C}\right.$ ]acetate. At intervals, $50 \mathrm{ml}$ or $100 \mathrm{ml}$ samples were centrifuged and the wax ester acids and alcohols isolated, and analysed by radio-GLC as described in Methods. The time taken for harvesting and addition of chloroform/methanol, which stops incorporation of radioactive precursor, was $15 \mathrm{~min}$, so that the time indicated is the real time of sampling.

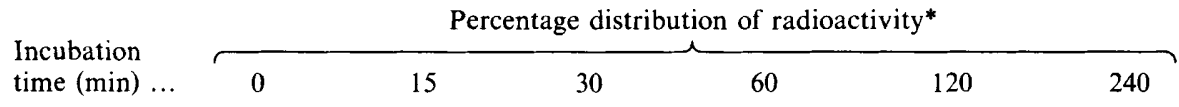

Wax fatty acids

Fatty acids

$\begin{array}{lcccccc}16: 0 & 9 \cdot 4 \pm 0 \cdot 7 & 8 \cdot 6 \pm 0 \cdot 5 & 8 \cdot 0 \pm 2 \cdot 2 & 9 \cdot 1 \pm 2 \cdot 6 & 8 \cdot 4 \pm 1 \cdot 5 & 9 \cdot 1 \pm 2 \cdot 8 \\ 16: 1 & 2 \cdot 3 \pm 2 \cdot 3 & 2 \cdot 1 \pm 2 \cdot 1 & 3 \cdot 1 \pm 3 \cdot 1 & 2 \cdot 2 \pm 2 \cdot 2 & 5 \cdot 2 \pm 5 \cdot 2 & 6 \cdot 7 \pm 6 \cdot 7 \\ 18: 0 & 83 \cdot 6 \pm 5 \cdot 7 & 80 \cdot 9 \pm 3 \cdot 7 & 76 \cdot 8 \pm 5 \cdot 0 & 70 \cdot 4 \pm 13 \cdot 4 & 56 \cdot 7 \pm 9 \cdot 0 & 43 \cdot 5 \pm 3 \cdot 0 \\ 18: 1 & 4 \cdot 8 \pm 3 \cdot 6 & 8 \cdot 3 \pm 1 \cdot 7 & 12 \cdot 0 \pm 4 \cdot 2 & 17 \cdot 8 \pm 6 \cdot 1 & 29 \cdot 6 \pm 2 \cdot 7 & 40 \cdot 7 \pm 3 \cdot 2 \\ \text { Unsaturated/saturated } & 0.076 & 0 \cdot 116 & 0 \cdot 178 & 0 \cdot 250 & 0.534 & 0 \cdot 901 \\ C_{18} / C_{16} & 7 \cdot 55 & 8 \cdot 34 & 8 \cdot 30 & 7 \cdot 41 & 6 \cdot 36 & 5 \cdot 33\end{array}$

Wax fatty alcohols

Fatty alcohol

$16: 0$

$16: 1$

$18: 0$

$18: 1$

Unsaturated/saturated

$\mathrm{C}_{18} / \mathrm{C}_{16}$

$\begin{array}{cccc}6 \cdot 1 \pm 0 \cdot 4 & 6 \cdot 8 \pm 0 \cdot 2 & 2 \cdot 6 \pm 3 \cdot 3 & 3 \cdot 9 \pm 4 \cdot 9 \\ \text { ND } & \text { ND } & \text { ND } & \text { ND } \\ 94 \cdot 0 \pm 0 \cdot 6 & 73 \cdot 1 \pm 1 \cdot 2 & 75 \cdot 0 \pm 0 \cdot 4 & 85 \cdot 0 \pm 18 \cdot 8 \\ \text { ND } & 20 \cdot 2 \pm 1 \cdot 1 & 22 \cdot 9 \pm 3 \cdot 6 & 11 \cdot 2 \pm 7 \cdot 0 \\ - & 0 \cdot 250 & 0 \cdot 295 & 0 \cdot 125 \\ 15 \cdot 4 & 13 \cdot 7 & 37 \cdot 6 & 24 \cdot 6\end{array}$

$3 \cdot 0 \pm 3 \cdot 7$
$\mathrm{ND}$
$68 \cdot 7 \pm 7 \cdot 1$
$28 \cdot 4 \pm 11 \cdot 0$
$0 \cdot 396$
$32 \cdot 3$

ND
ND
$74 \cdot 0 \pm 0 \cdot 3$
$26 \cdot 1 \pm 0 \cdot 3$
$0 \cdot 350$
0

ND, Not detected.

* Values are the mean \pm S.E.M. $(n=2)$.

Table 2. Distribution of radioactivity in wax ester acids and alcohols of $M$. cryophilus incubated with $\left[1-{ }^{14}\right.$ C $]$ palmitic acid

Cultures $(300 \mathrm{ml})$ were incubated at $20^{\circ} \mathrm{C}$ with $60 \mu \mathrm{Ci}$ of $[1-14 \mathrm{C}]$ palmitic acid and treated as described in Table 1.

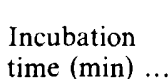

$\overbrace{0}^{\text {Percentage distribution of radioactivity* }} \begin{aligned} & \text { * } \\ & 15\end{aligned}$

Wax fatty acids

\section{Fatty acids}

$16: 0$

$16: 1$

$18: 0$

$18: 1$

Unsaturated/saturated

$\mathrm{C}_{18} / \mathrm{C}_{16}$

$95 \cdot 1 \pm 1 \cdot 4$
$2 \cdot 0 \pm 1 \cdot 2$
$2 \cdot 2 \pm 1 \cdot 8$
trace
0.021
0.023

$85 \cdot 9 \pm 3 \cdot 6$
$1.6 \pm 1 \cdot 2$
$11 \cdot 8 \pm 4.9$
$0.4 \pm 0.4$
0.021
0.139

$\begin{array}{cc}94.0 \pm 1.7 & 94.1 \pm 0.6 \\ 2.4 \pm 0.7 & 1.9 \pm 0.6 \\ 2.7 \pm 0.0 & 2.7 \pm 0.6 \\ \text { trace } & \text { trace } \\ 0.025 & 0.020 \\ 0.028 & 0.028\end{array}$

$91 \cdot 6 \pm 3 \cdot 7$
$2 \cdot 5 \pm 0 \cdot 1$
$3 \cdot 2 \pm 0 \cdot 9$
$2 \cdot 8 \pm 2 \cdot 8$
$0 \cdot 056$
$0 \cdot 064$

$87 \cdot 3 \pm 4 \cdot 1$
$2 \cdot 5 \pm 1 \cdot 7$
$4 \cdot 1 \pm 0 \cdot 8$
$5 \cdot 4 \pm 2 \cdot 9$
$0 \cdot 086$
$0 \cdot 106$

$84 \cdot 3 \pm 3 \cdot 6$

Wax fatty alcohols

Fatty alcohol

$16: 0$
$16: 1$
$18: 0$
$18: 1$
Unsaturated/saturated
$C_{18} / C_{16}$

$\begin{array}{cr}75.2 \pm 1.6 & 79.5 \pm 6.8 \\ 1.5 \pm 0.7 & 4.5 \pm 2.5 \\ 20.5 \pm 0.2 & 13.5 \pm 5.0 \\ \text { ND } & 3.5 \pm 1.9 \\ 0.016 & 0.086 \\ 0.267 & 0.202\end{array}$
$73 \cdot 5 \pm 3 \cdot 1$




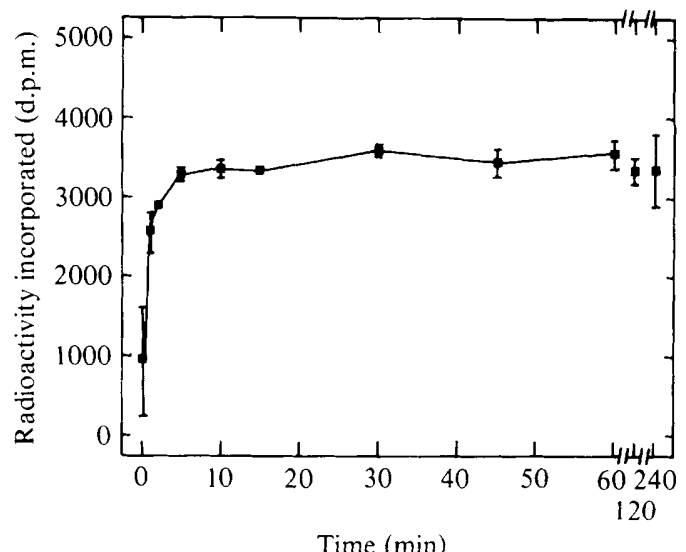

Fig. 3. Incorporation of $\left[1^{14} \mathrm{C}\right]$ stearoyl-CoA into wax esters of $M$. cryophilus. Lysate $(25 \mathrm{ml})$ prepared from $250 \mathrm{ml}$ of a late-exponential culture as described in Methods, was incubated with $0.4 \mu \mathrm{Ci}\left[1-^{14} \mathrm{C}\right]-$ stearoyl-CoA. At intervals samples $(1 \mathrm{ml})$ were removed directly into chloroform $/$ methanol and the wax esters isolated by TLC as described in Methods. Values are means \pm S.E.M. $(n=2)$.

\section{$\alpha$-Oxidation studies}

The wax ester fatty acids and fatty alcohols isolated from bacteria incubated with sodium $\left[\mathrm{U}-{ }^{14} \mathrm{C}\right]$ acetate or $\left[1-{ }^{14} \mathrm{C}\right]$ palmitic acid were subjected to chemical $\alpha$-oxidation in order to reveal the pattern of radioactive labelling along the carbon chain. When acetate was the precursor, both acid and alcohol were labelled relatively uniformly along the length of the carbon chain. In contrast, when palmitate was the precursor the radioactivity remained at the original $1{ }^{-14} \mathrm{C}$ position with very little $(<5 \%)$ randomization of the label.

\section{Biosynthesis of wax esters from acyl-CoA}

Incubation of a bacterial lysate with $\left[1-{ }^{14} \mathrm{C}\right]$ stearoyl-CoA led to a large proportion $(64 \cdot 1 \%$ after $10 \mathrm{~min}$ ) being $\beta$-oxidized. There was a rapid incorporation of radioactivity into wax esters, which reached a plateau after 5-10 min (Fig. 3), when 10.9\% of the added stearoyl-CoA was in wax esters. The remainder of the substrate was incorporated into phospholipids. Of the radioactivity incorporated into wax esters, approximately equal amounts were recovered from the fatty acid and fatty alcohol moieties (1090 and 973 d.p.m. per ml original lysate, respectively) after a $4 \mathrm{~h}$ incubation with stearoyl-CoA.

\section{DISCUSSION}

Before discussing the present data on wax ester biosynthesis in $M$. cryophilus, it is appropriate to consider the three possible metabolic routes based on studies in animal and plant tissues: (i) reversal of an esterase reaction, resulting in the esterification of a fatty acid with a fatty alcohol, (ii) acyl group transfer from a phospholipid to a fatty alcohol catalysed by an acyl transferase, and (iii) direct esterification of an activated fatty acid (e.g. acyl-CoA) with a fatty alcohol catalysed by an acyl-CoA : alcohol transacylase.

The first route, direct esterification of a fatty acid, has not been demonstrated in lipid biosynthetic pathways, including wax ester biosynthesis (e.g. see Pollard et al., 1979) and so will not be considered further here, particularly in view of the following discussion.

The second route, acyl transfer from a phospholipid to a wax ester, seems unlikely in $\boldsymbol{M}$. cryophilus, since the amount of radioactivity from palmitate found in wax esters decreased whilst that in phospholipids was increasing (Fig. $1 b$ ). Although this does not prove that there is acyl transfer in the reverse direction, i.e. from wax esters to phospholipids, it probably rules out the second route as a mode of synthesis of wax esters. Wu et al. (1981) also showed that jojoba seed does not synthesize wax esters at the expense of phosphatidylcholine acyl chains. 
exogenous precursor

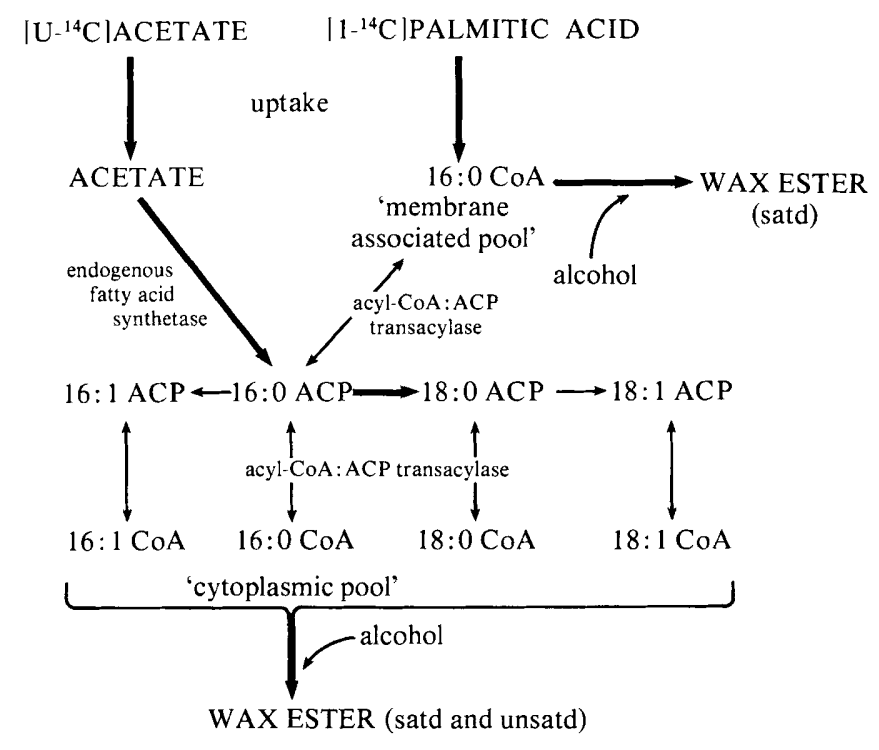

Fig. 4. Proposed routes of wax ester biosynthesis in $M$. cryophilus

It would appear, therefore, that the most probable pathway of wax ester biosynthesis in $M$. cryophilus is by an acyl-CoA:alcohol transacylase. Direct proof of this was obtained by incubating cell-free extracts with stearoyl-CoA, which was incorporated readily into wax esters (Fig. 3). This is the most common mechanism for wax ester biosynthesis, being found in algae (Kolattukudy, 1970), plants (Kolattukudy, 1967), animals (Grigor \& Harris, 1977), copepods (Sargent et al., 1976) and another bacterium, Mycobacterium smegmatis (Wang et al., 1972).

The kinetics of labelling from radioactive precursors (Fig. $2 a, b$ ) and the degradation studies using $\alpha$-oxidation indicated that the alcohols were derived directly from fatty acids. The reductase that carries out this reaction in $M$. cryophilus is membrane-bound (G. M. Lloyd, unpublished results).

The two major classes of lipid in $M$. cryophilus are phospholipids and wax esters, and it is relevant to consider whether they draw acyl chains from a common or separate pools. Although acyl-CoA is a substrate for wax ester biosynthesis (see above), it does not serve as substrate for desaturation and is probably not the main donor for phospholipid biosynthesis (Foot et al., 1983); the latter is probably served by acyl-ACP (Raetz, 1978), but stearoyl-ACP is not converted directly to wax esters by cell-free extracts of $M$. cryophilus (Foot, 1980). Thus we can envisage an acyl-CoA 'track' leading to wax esters and an acyl-ACP 'track' leading to phospholipids, the tracks being connected by an acyl-CoA : ACP transacylase enzyme (Fig. 4).

The differences in the labelling patterns in wax esters depending on whether the precursor is acetate or palmitate can be explained on the basis of the origin of the acyl-CoA (Fig. 4). Exogenous acetate is taken up and metabolized by fatty acid synthetase to give a mixture of endogenous 16:0-ACP and 18:0-ACP. These ACP-thioesters are subject to a variety of metabolic interconversions including phospholipid biosynthesis, desaturation and formation of acyl-CoA. The latter is the substrate for wax ester synthetase, and initially after addition of radioactive acetate this produces saturated wax esters containing $\mathrm{C}_{18}$ (and some $\mathrm{C}_{16}$ ) acids and alcohols. These saturated wax esters are not desaturated per se, and the appearance of unsaturated wax esters, containing largely $C_{18: 1}$ acids and alcohols, results from the equilibration of unsaturated acyl chains from phospholipids or acyl-ACP (cf. Foot et al., 1983) with the cytoplasmic acyl-CoA pool. 
In contrast, exogenous fatty acids, such as palmitate, are converted directly to acyl-CoA as part of the uptake mechanism (Klein et al., 1971). Since the wax ester synthetase is membranebound (G. M. Lloyd, unpublished results), this would provide a distinct pool of palmitoyl-CoA at the membrane for wax ester synthesis. Therefore, the addition of exogenous palmitate leads initially to saturated wax esters containing essentially $C_{16}$ (with very few $C_{18}$ ) acids and alcohols. Once in the wax esters, the acids and alcohols undergo little equilibration with the cytoplasmic pools of acyl-CoA and acyl-ACP. So there is much less of a time-dependent change to unsaturated wax ester (containing $\mathrm{C}_{18: 1}$ acid and alcohol) synthesis, compared with experiments in which acetate is the precursor.

In comparison with these results, it has been suggested that in the jojoba seed there are two distinct acetyl-CoA compartments (Shine et al., 1976; Ohlrogge et al., 1978). Compartment I contains de novo fatty acid synthesis as well as palmitoyl-ACP elongation and stearoyl-ACP desaturase pathways, the entire biosynthetic sequence to oleate appearing to take place on an ACP 'track'. Unesterified fatty acid, released from this ACP 'track', is considered to be transported into compartment II where it is converted to an acyl-CoA thioester, elongated and incorporated into a wax ester.

The pathways described above for $M$. cryophilus, summarized in Fig. 4, provide an explanation of the labelling patterns observed. Although they may be an oversimplified view of the mechanisms operating in vivo, they provide a basis for future experiments on wax ester biosynthesis in this psychrophilic bacterium.

The authors wish to thank the SERC for financial support.

\section{REFERENCES}

Dean, R. B. \& Dixon, W. J. (1951). Simplified statistics for small numbers of observations. Analytical Chemistry 23, 636-638.

Foot, M. (1980). Studies on a bacterial $A^{9}$ desaturase. Ph.D. thesis, University of Wales, U.K.

Foot, M., JefFcoat, R. \& Russell, N. J. (1983). Some properties, including the substrate in vivo, of the $\Delta^{9}$. desaturase in Micrococcus cryophilus. Biochemical Journal 209, 345-353.

Garbus, J., Deluca, H. F., Loomans, M. E. \& STRONG, F. M. (1963). The rapid incorporation of phosphate into mitochondrial lipids. Journal of Biological Chemistry 238, 59-63.

Grigor, M. R. \& Harris, E. L. (1977). Wax ester synthesis in the mouse preputial gland tumour. Biochimica et biophysica acta 488, 121-127.

KATES, M. (1972). Techniques of Lipidology. Isolation, Analysis and Identification of Lipids, 1st edn, p. 519. Amsterdam: North-Holland Publishing Co.

Klein, K., Steinberg, R., Fiethen, B. \& Overath, P. (1971). Fatty acid degradation in Escherichia coli. An inducible system for uptake of fatty acids and further characterization of old mutants. European Journal of Biochemistry 19, 442-450.

Kolattukudy, P. E. (1967). Mechanisms of synthesis of waxy esters in Broccoli (Brassica oleracea). Biochemistry 6, 2705-2717.

KolatTUKUDY, P. E. (1970). Reduction of fatty acid to alcohols by cell free preparations of Euglena gracilis. Biochemistry 9, 1095-1102.

Ohlrogge, J. B., Pollard, M. R. \& Stumpf, P. K. (1978). Studies on biosynthesis of waxes by developing jojoba seed tissue. Lipids 13, 203-210.

Pollard, M. R., McKeon, T., Gupta, L. M. \& STUMPF, P. K. (1979). Studies on biosynthesis of waxes by developing jojoba seed. II. The demonstration of wax biosynthesis by cell-free homogenates. Lipids 14, 651-662.

RAETZ, C. R. H. (1978). Enzymology, genetics and regulation of membrane phospholipid synthesis in Esherichia coli. Microbiological Reviews 42, 614-659.

RUSSELL, N. J. (1974). The lipid composition of the psychrophilic bacterium Micrococcus cryophilus. Journal of General Microbiology 80, 217-225.

Russell, N. J. \& Volkman, J. K. (1980). The effect of growth temperature on wax ester composition in the psychrophilic bacterium Micrococcus cryophilus ATCC 15174. Journal of General Microbiology 118, 131-141.

SANDERCOCK, S. P. \& Russell, N. J. (1980). The elongation of exogenous fatty acids and the control of phospholipid acyl chain length in Micrococcus cryophilus. Biochemical Journal 188, 585-592.

Sargent, J. R., Lee, R. F. \& Nevenzel, J. C. (1976). Marine waxes. In Chemistry and Biochemistry of Natural Waxes, pp. 49-91. Edited by P. E. Kolattukudy. Amsterdam: Elsevier.

Shine, W. E., Mancha, M. \& StumpF, P. K. (1976). Fat metabolism in higher plants: the function of acyl thioesterases in the metabolism of acyl coenzyme A and acyl-acyl carrier proteins. Archives of Biochemistry and Biophysics 172, 110-116.

Wang, L., TAKayama, K., Goldman, D. S. \& SCHNOES, H. K. (1972). Synthesis of alcohol and wax ester by a cell-free system in Mycobacterium tuberculosis. Biochimica et biophysica acta 260, 41-48.

Wu, X-Y. Moreau, R. A. \& StumpF, P. K. (1981). Studies of biosynthesis of waxes by developing jojoba seed. III. Biosynthesis of wax esters from acyl$\mathrm{CoA}$ and long chain alcohols. Lipids 16, 897-902. 